\title{
Influence of Youth Subculture on the Ideological Guidance of Ideological and Political WeChat Public Number
}

\author{
Ranni Zhang ${ }^{1,2}$, Ze Chen ${ }^{2} \&$ Songping Yang ${ }^{3}$ \\ ${ }^{1}$ School of Journalism and Communication, Jinan University, Guangzhou, China \\ ${ }^{2}$ School of Humanities, Jinan University, Zhuhai, China \\ ${ }^{3}$ Zhuhai Campus, Jinan University, Zhuhai, China \\ Correspondence: Songping Yang, Qianshan Road, Zhuhai Campus, Jinan University, Zhuhai, China. E-mail: \\ ysp08@163.com
}

Received: February 23, 2019

Accepted: March 3, 2019 Online Published: March 29, 2019

doi:10.5539/ass.v15n4p102

URL: https://doi.org/10.5539/ass.v15n4p102

The paper reported here is sponsored by the project of Guangdong Educational Science Planning Topic (The 19th CPC National Congress Spirit Research Project), Project name: Research on Linkage Mechanism of Ideological and Political Theory Course and New Media and New Technology in New Era, Project Grant No. 2016 GZMZGJ04.

The research is also the staged achievement of the project: 2017 Guangzhou Philosophy and Social Sciences "13th Five - Year Plan" Special Topic on Marxist Theory and Practice, Project name: Research on Making Ideological and Political Work Live with New Media and New Technology, Project Grant No. 2018JKSJD83.

\begin{abstract}
An important proportion of the audiences of the ideological and political WeChat public are young people, and the "youth subculture" which has a great influence on the ideological and political WeChat public number prevailing among the audience youth. "Guangdong students' federation" WeChat public number and "Jinan University Youth League Committee" WeChat public number are selected to do comparative study transforming the use of youth subculture, its advantages and deficiencies can be explored, and the ideological and political public number transformation and utilization of youth subculture optimization recommendations can be drawed.
\end{abstract}

Keywords: youth subculture, public number, ideological guidance, expression pack

\section{Influence of Youth Subculture on College Students' Ideological and Political Education}

\subsection{The Connotation of Youth Subculture}

In a broad sense, subculture refers to a group of lifestyles that have cultural elements that are not available to other groups (Derks, 2007). There is no specific scope limitation for youth subculture, but it always has corresponding characteristics by default (Aceros, Belli, \& Ninova, 2019). In the youth subculture, the youth group yearns for recognition and recognition. They wander around the center and the edge (Williams, 2019), share their thoughts and preferences in the group in an open, convenient and diversified way, and express and show their diverse and complex attitudes externally. Such youth groups are generally in a specific cultural context, and their thoughts, concepts, behaviors, etc. have different styles and styles from mainstream cultural groups. In the face of real social contradictions, they will be solved in their own unique ways. With the reform in education, teaching management has had to change. Teaching secretaries play an important role in education management. Especially, working in an English teaching and international environment, the secretaries have to face new challenges, and they require new skills to adapt to the environment. Thus, we have to discuss how these secretaries can adapt to the environment of using English as a working language; and how they can improve their work quality and efficiency to increasingly upgrade the education management level.

In all kinds of youth subcultures, the network youth subculture has dominated and dominated. Network youth subculture refers to a youth subculture form that is generated in the network age and can be spread and reproduced through the development of network technology (Liao, 2013). The Internet is an important carrier of the subculture of Internet youth. In the era of traditional media, teenagers use platforms such as newspapers, 
radio, television and art to create subcultural circles and conduct identity confirmation. In the new media era, teenagers use digital technology and symbols to create new subcultures (Zhou, 2011). The main representative products of the network youth subculture reproduction are network buzzwords, paragraphs, expression packs and so on.

\subsection{The Positive Impact of Youth Subculture on the Ideological and Political Education of College Students}

\subsubsection{Expanding the Content of Ideological and Political Education}

The attention and thinking of young people on social issues is the origin of youth subculture( $\mathrm{Xu}, 2013)$. The ideological and political education of the content of college students is conducive to enhancing the interest and attention of college students on the content of ideological education and cultivating their social observation ability. It not only expands the content of ideological and political education for college students, but also provides new ideas and innovative ways for the implementation of ideological and political education for college students.

\subsubsection{Provide an Innovative Carrier for Ideological and Political Education}

Different from the communication characteristics of mainstream culture, the communication of youth subculture does not depend on specific media and carriers, but it continues to expand its communication channels with the development of science and technology and the innovation of media. In recent years, the large-scale application of new media such as QQ, Weibo and WeChat has made the form and carrier of ideological and political education of college students more diversified, which has a great effect on the improvement of the effectiveness of ideological and political education.

\subsubsection{Injecting Vitality into Ideological and Political Education}

College students are active in thinking and enriching their ages. They actively engage in creative and liberating activities. On the one hand, compared with the characteristics of traditional ideological and political education, the form of youth subculture is more relaxed and active. On the premise of guaranteeing its authority, ideological and political education is presented in front of college students in a more relaxed and happy way, making ideological and political education more dynamic and enhancing the effect of education. On the other hand, youth subculture can help stimulate Young people's enthusiasm for reflection and exploration of social issues effectively complements the connotation of college students' ideological and political education.

\section{The Importance of the Ideological and Political Public Number to the Transformation and Utilization of Youth Subculture}

\subsection{The Combination of Youth Subculture and College Students' Lead Work Achieves the Specific Effect of "Leading"}

Thought-led work refers to a planned, organized, and affiliated member of a political party, class, or social group, exerting influence on its ethics and political views to form an ideological behavior that meets the expectations of the class and political party. Social practice activities. All along, thought-led work is the main content of college education, and it is highly valued by the state and society. Its main content includes mental and moral education in addition to ideological and political education. In the context of social transformation, the ideological leadership of college students has made tremendous contributions to cultivating the core values of the young student party and the state, to the great rejuvenation of the motherland, and to cultivating the country's future successors. Of course, this is also the educational direction that colleges and universities must grasp to lead their work. As the main carrier of youth subculture, college students are the main representatives of the youth group. Without this group, the youth subculture loses its meaning. The combination of youth subculture and college students' thought-leading work has made college students play an important role in the connection between passiveness and subjectivity, and has achieved the specific effect of "leading".

\subsection{Youth Subculture Plays a Continuous Role in the Process of College Students' Thought-Leading Work}

The process of leading work leads to the exchange of energy and information with the outside, to falsify the truth, to absorb positive elements for their own use, and in modern society, the existence of youth subculture is ubiquitous, and its state is not what thought leads the work. An important factor in Xiaoyan. In particular, the ideological and political public number born in response to the development of the Internet era, its original meaning is to keep pace with the times and to close the distance between the audience and the thought to lead the work. The combination of the ideological and political public number and the youth subculture is in keeping with the requirements of the times and meeting the requirements of the audience. The youth subculture will continue to play a role in the ideological and leadership work of college students. 


\section{Case Study on Transformation and Utilization of Youth Subculture by Ideological and Political Public Numbers}

According to the definition of WeChat official website, WeChat public platform is the platform that operators provide information and services for WeChat users through public accounts. Any organization or individual can apply for the subscription number of the public account, establish the "We-Media", and edit the picture and text information, voice and video collection through the background management, and then send to the people who subscribe to the public account. As a representative product of the ideological and political work and the network era, the ideological and political public number has been the most characteristic of "advancing with the times" since its birth. It needs to use the WeChat public network platform to successfully complete the thought-leading work. To carry out, it also requires the integration of the public life, reducing the sense of distance between the ideological and political tweets and the ordinary people, that is, their audience. Therefore, the ideological and political public number has developed earlier and more maturely for the transformation and utilization of the network youth subculture. Various types of ideological and political tweets now use online hot words, network segments and expression packs.

In the transformation and utilization of the youth subculture by the ideological and political public, the use of expression packs is the most mature. The expression pack is one of the network expression symbols. Its form is mainly static and dynamic pictures. It can contain not only expressions, movements, etc., but also text. Because the expression package has the characteristics of simple, straightforward, clear and interactive, it has become the most commonly used communication symbol on the Internet today (Zhang, 2016). For example, the expression package of Dakang's secretary from the hot-selling drama series "The Name of the People" is popularized by young people who spontaneously choose and use their imagination to create their own works (Dou, 2018). Such cases have a direct impact on the interaction between youth subculture and mainstream culture. Spreading positive thoughts in the form of "emoticons" will greatly encourage young people's enthusiasm to accept them. Young people, on the other hand, are used to using emojis to express their emotions and thoughts in a positive way (Derks, Bos, \& von Grumbkow, 2007). This paper takes the application of the expression pack in the analogy as an example by using the ideas issued by the "Jinan University Youth League Committee" WeChat public number and "Guangdong students' federation" WeChat public number as an example.

\section{1 "Guangdong Students' Federation" Public Number Thought Leads the Use of Tweet Expression Package Examples}

Founded in 1955, Guangdong Students' Federation (GDSF) is a joint organization of Guangdong Students' union, graduate Students' union, secondary Students' union and Students' Federation of cities and counties under the leadership of the communist party of China. "Guangdong students' federation" WeChat public number is the WeChat public platform of the Guangdong Student Union. It is affiliated to the Guangdong Provincial Committee of the Communist Youth League. It is jointly operated by the Guangdong Provincial Youth League School and the Guangdong Student Union. Its purpose is to "based on students and services." student". Compared with the "Guangdong Communist Youth League", which is also affiliated to the Guangdong Provincial Youth League Committee and operated independently, and the target audience is mainly for all the Communist Youth League members in the province, the "Guangdong students' federation" is the main operator of the university and its audience. The group is divided into more than 2 million college students in Guangdong Province, and the operation mode is closer to the WeChat public platform at the institution level. At the same time, the author used to be the editor of WeChat public account of "Guangdong students' federation" and have a good understanding of its operation mode. Taking the WeChat official account of "Guangdong students' federation" as one of the samples of this investigation and study, the conclusion will be typical and easy to be promoted.

In the ideological and political tweets, the application of the expression pack, "Guangdong students' federation" WeChat public number has accumulated a lot of experience. First of all, Guangdong Federation of Students has its own two cartoon characters, "Group" and "Learning", which means that the work of the Communist Youth League is closely related to the student work. The cartoon image is playful and lively, and a large number of expression packs are derived based on various major events.

Secondly, all kinds of emoticons that lead the work theme are widely used in the text, which helps the audience to understand and deepen the important role of the ideological and political topics. At the same time, the content of the article is more vivid, and the reading pleasure is reduced. The sense of distance and sense of alienation between the ideological and political tweets and the audience. According to the tweet "Qing Ma Si "Enjoy" published by the "Guangdong students' federation" WeChat public on October 29, 2018: a hundred-year plan, 
education-oriented South Guangdong Youth said Youth Study, for example, the text of General Secretary Xi Jinping Produced into a "daily-learning 'study' expression pack, in this way spread the important speech of General Secretary Xi Jinping, very fashionable and grounded, more acceptable to the audience.

In the end, Guangdong Federation of Scholars is not satisfied with just inserting expression packs in tweets and starting to create special WeChat chat expressions for large-scale thought-leading work projects. For example, the Guangdong Youth College Youth League, the Guangdong Provincial Education Department, and the Guangdong Student Union jointly launched the "Lighthouse Project" for the action of the young college students in Guangdong. The "Guangdong students' federation" public number was released on October 12, 2018. "Lighthouse Project" exclusive expression pack is on the line!" In the article, the official announcement of the "Lighthouse Project" exclusive WeChat expression "DengDeng The first bullet of the expression pack", took the first step of using WeChat expression to publicize the thoughts of college students to lead the work It is a major innovation from the audience college students to passively receive the expression package information from the tweet to guide the college students to actively use the ideas to lead the work-related expressions to learn relevant information.

\section{2 "Jinan University Youth League Committee" Public Number Thought Leads the Use of Tweet Expression Packs}

"Jinan University Youth League Committee" WeChat Public No. is a WeChat public platform managed by the Youth League Committee of Jinan University. The university's university students are the main operators. The audience is mainly the teachers and students of Jinan University. It is a typical school-level WeChat public platform. It is also an important window for the Communist Youth League Committee of Jinan University to engage in ideological and political work for college students. The "Jinan University Youth League Committee" publicity's thought-leading tweets also have a large number of expression packs, and they also have their own unique aspects in the use of expression packs. The author also participated in the operation and management of the "Jinan University Youth League Committee" WeChat public platform, mastered a large number of background data, and the research samples were authentic and objective. Taking "Jinan University Youth League Committee" WeChat official account as one of the samples of this investigation and research, the conclusion obtained will be typical and easy to be promoted.

The public's speech on November 1, 2018, "What did we learn from the speech of General Secretary Xi Jinping?" In the article "Southern Youth says · Youth Learning", the article begins with the quotation of General Secretary Xi Jinping's quotation. In the text, there is also a cartoon expression package of "Southern Guangdong Youth", which is in line with the theme of the article; the public number "On October 18th, 2018, "Cannot do a promise," you must do "one In the article "Nuo Ermao", a large number of expression packs are also used, including the popular "Wang Jingze" expression pack and the "Panda Head" expression pack on the Internet. This is a boring and cumbersome procedure for paying the tour fee. The topic adds a certain amount of fun, and it is more attractive to readers to read the article content.

\section{3 "Jinan University Youth League Committee" "Guangdong Students' Federation" Public Number Expression Package Comparison}

The two official WeChat public numbers have fully transformed the use of the youth network subculture consciousness. In the ideological and political tweets, a large number of cartoon expression packs that match the theme are used, and the relative expression packs are used to increase the fun of reading relatively boring ideological and political tweets. Reduce the sense of distance between the content promoted by ideological and political tweets and the audiences of the audience, so as to improve the audience's acceptance.

In terms of the comparison between the two public numbers in the use of expression packs, the "Guangdong students' federation" WeChat public account has more experience than the "Jinan University Youth League Committee" WeChat public account, especially in the timeliness and originality of the expression pack. The aspect is far ahead. At the beginning of the release of large-scale thought-leading work projects at the national, provincial, and municipal levels, Guangdong Federation of Scholars will often launch a series of emoticon images or cartoon images, project cartoon logos, etc., or even start at the first time. Trying to make ideas to lead the work-related WeChat chat expression package, dare to break through innovation in form and content, closely follow the hot trend of ideological and political work, and achieve a good response in the audience; and the "Jinan University Youth League Committee" WeChat public account also uses a large number of cartoon expression packs in ideological and political analogies, but the originality of the expression pack is not high, and it is mostly the forwarding network popular expression pack or the related expression pictures produced by Guangdong students' federation. 
The author believes that there are two points: First, the gap between the public operation team, the operation team of the "Guangdong students' federation" WeChat public account is mainly selected from the interviews among outstanding student leaders in major universities, or The responsible teachers of each school are recommended to produce. The main component of the operation team of the "Jinan University Youth League Committee" WeChat public number is that the second-grade ministerial students of several universities lead dozens of first-year university students who are interested in the operation of the public number and have some experience. There is a certain gap in the composition of the operation team. The strength gap of the operation team will be reflected in the quality of the tweet content, as well as the production and selection of the expression package. Second, the gap in the operation mode of the public number is directly under the jurisdiction of the Guangdong Provincial Youth League Committee. The WeChat public number of the leader, the "Guangdong students' federation" WeChat public platform can obtain a large number of first-hand information on large-scale youth thought-leading projects at the national, provincial and municipal levels, facilitating more comprehensive publicity and promotion work. School-level WeChat public platform like "Jinan University Youth League Committee" can only carry forward further thought-leading work in the school by forwarding the push content released by Guangdong students' federation, or on the basis of secondary creation. Its content and expression package the originality, timeliness and other aspects will be far less than the "Guangdong students' federation" WeChat public with a lot of relevant information. The number is different; the two are different audiences. The "Guangdong students' federation" WeChat public platform is aimed at nearly two million college students in Guangdong Province. It shoulders more serious and heavy thoughts to lead work tasks and has stronger authority. Sexuality, most of the expression packs popular in the Internet are not suitable for their thought transfer, and their operators need to adopt innovative creation for discourse expression. The "Jinan University Youth League Committee" class-based WeChat public platform is less serious in the school information release, and can use a more humorous expression package for discourse expression, and there is little demand for re-creating the expression package.

\section{Research Conclusions and Recommendations}

\subsection{Analysis of the Current Situation of the Transformation of the Ideological and Political Public Number Using the Youth Subculture}

In terms of the influence, appeal and appeal of mainstream value guidance, the current college WeChat public account generally has the following problems: the lack of interaction with the audience students, and the low degree of communication among the audience students. The related expression packs mentioned above can only be used in specific tweets, and cannot be recognized by most audiences. They cannot be fully integrated into the daily life of college students, that is, completely out of the traditional one-way communication mode of mainstream value media.

\subsection{Relevant Optimization Suggestions}

\subsubsection{Fully Understand the Youth Subculture}

Reflecting on the frequent use of expression packs by various public education standards, on the one hand, weakening the serious topics, rational perspectives and political ideology in the mainstream ideological and political media discourse, on the other hand, blurring the boundaries of mainstream value communication, so It is possible to be close to the daily life of college students and change their minds to lead the stereotyped image of work in the minds of college students.

Firstly, it should have a deep understanding of the communication mechanism of youth subculture, clarify its discourse style and function characteristics, and formulate corresponding appropriate communication strategies for its unique characteristics, and find appropriate in the discourse system of education and the discourse system of youth subculture. Balance the point and maintain the seriousness and authority of mainstream value communication.

\subsubsection{Break the One-Way Communication Mode and Interact with the Audience in Two-Way}

Operators of the ideological and political public number should give full play to the advantages of using the new media platform, strengthen the two-way communication and interaction between the "point" and the "point", and obtain instant and sufficient information feedback to invite the audience to participate in the thought-leading. At work, it stimulates the interest and enthusiasm of young scholars, so as to achieve the dissemination effect of "listening to the youth, feeling young, thinking about the youth". For example, for college students to hold expression packs, the audience will use their own methods to lead the work, and on the one hand, they can get recognition from the youth groups. On the other hand, they can also deepen the students' dissemination of 
mainstream values while creating expression packs. Know and play a better communication effect.

\section{References}

Aceros, J. C., Belli, S., \& Ninova, M. (2019). Often it is because of who is doing it. The production of a youth subculture's image through talk. Journal of Youth Studies, 22(1), 46-65. https://doi.org/10.1080/13676261.2018.1477124

Derks, D., Bos, A. E. R., \& von Grumbkow, J. (2007). Emoticons and social interaction on the Internet: the importance of social context. Computers in Human Behavior, 23(1), 842-849. https://doi.org/10.1016/j.chb.2004.11.013

Williams, J. P. (2019). Subculture's Not Dead! Checking the Pulse of Subculture Studies through a Review of 'Subcultures, Popular Music and Political Change' and 'Youth Cultures and Subcultures: Australian Perspectives'. Young, 27(1), 89-105. https://doi.org/10.1177/1103308818761271

Dou, L. (2018). Construction of ideological and political education discourse under the influence of online youth subculture-a case study of "dakang secretary" emoji. Comparative Study of Cultural Innovation, 2(9), 1-2.

Liao, Y. H. (2013). Study on the influence of youth subculture on ideological and political education of college $\begin{array}{llll}\text { students and countermeasures. China } & \text { Market, } 204 .\end{array}$ https://doi.org/:10.3969/j.issn.1005-6432.2013.42.079

$\mathrm{Xu}, \mathrm{L}$. (2013). Research on college students' ideological and political education from the perspective of youth subculture. School party building and ideological education. The Party Building And Ideological Education in Schools, (22), 40-41+46. https://doi.org/10.3969/j.issn.1007-5968.2013.10.012

Zhou, M., \& Yang, F. (2011). New media environment and network youth subculture phenomenon. Journalism enthusiasts of China, (19), 24-25. https://doi.org/10.16017/j.cnki.xwahz.2011.19.033

Zhang, N. (2016). Deconstruction as resistance: youth subculture analysis of "emoji war". Modern Communication. Journal of Communication University of China, 38(9), 126-131. https://doi.org/10.3969/j.issn.1007-8770.2016.09.025

\section{Copyrights}

Copyright for this article is retained by the author(s), with first publication rights granted to the journal.

This is an open-access article distributed under the terms and conditions of the Creative Commons Attribution license (http://creativecommons.org/licenses/by/4.0/) 